\title{
Service-Learning in the Ecuadorian Andes through Spanish, English and Kichwa Voicing
}

\author{
Verónica Yépez-Reyes \\ Associate Professor of Science in Communication, Dean of College of \\ Communication, Linguistics and Literature, Pontificia Universidad Católica \\ del Ecuador, Quito, Ecuador \\ vyepezr@puce.edu.ec
}

Karina A. Ortiz Pacheco

Associate Professor of Language and Literature, College of Communication, Linguistics and Literature, Pontificia Universidad Católica del Ecuador, Quito, Ecuador

kortiz652@puce.edu.ec

\begin{abstract}
Community engagement projects create an avenue for university students and faculty to interact with local communities. These endeavors place together groups with different worldviews, cultures, and languages. Service-Learning (SL) has acquired novelty in academic circles; however, there has been limited research analyzing what happens with intercultural communication. This article attempts to fill this gap by asking how intercultural communication is shaped through SL. Research was conducted on a community engagement project in the Andean paramo of Chugchilán, Ecuador involving faculty, students, and members of the indigenous community. For the analysis, a blended design of transcendental phenomenology and SL methodology was used to analyze how participants perceive and make sense of their experience. From a linguistic perspective, we used both bilingualism and diglossia to analyze intercultural communication during the SL experience. The findings show that SL is a valid methodology that can increase intercultural communication while developing cultural competency between participants of the project. Finally, the study considers the revitalization of indigenous languages to be a fundamental step for a global intercultural world.
\end{abstract}




\section{Keywords}

Service-Learning - intercultural communication - diglossia - bilingualism - Kichwa

\section{Introduction}

Higher education leans upon three substantive functions: teaching, research, and community outreach. All of them, at some point, are interrelated and interdependent in the construction of significant learning. González, Yépez-Reyes, and García (2019) consider community outreach the foundation of higher education, and the purpose of teaching and research combined lies in their ability to transform everyday reality through appropriate practices, which is a two-way transfer of knowledge. Welch (2016) states that "the primary task and educational purpose of colleges and universities are to avail their intellectual resources to the community" (38). While higher education has prioritized the dissemination of knowledge, the historical mission of higher education is to serve the public and find the ways to engaged with the community.

Consequently, community engagement programs serve a double function: they allow higher education institutions the opportunity to participate in social, economic, cultural, and civic issues while preparing students for their lives beyond the university. Service-Learning, SL -a key concept in our paper, is elaborated in the next section- gives participants the chance to articulate their skills and enhance their understandings, as well as engage in critical and constructive dialogue (Fung 2017). In some cases, this implies transcending the cultures, languages, and worldviews of the participants.

In Ecuador, there are 14 different indigenous nationalities and 13 indigenous languages which are the official languages in their own territories (Haboud 2019). The Ecuadorian Constitution recognizes Spanish as the official language, and Spanish, Kichwa and Shuar as official languages for intercultural relations. Linguistic diversity can be misleading because even though the country is linguistically diverse, Spanish is the dominant language. Spanish is spoken by most of the population and is used in the government, education, and economy. Kichwa is the most common indigenous language in Ecuador and is mainly used in the rural areas of the Ecuadorian Andes and Amazon.

Kichwa is a variant of the Andean Quechua's linguistic family which is mostly spoken in Ecuador. Howard (2011) explains that this language is better described as a "language family" due to the vast range of its variant forms spoken in Ecuador, Peru, Bolivia, Colombia, and Argentina. The Spanish conquest of South America led to the first encounters between the Spanish and Kichwa language speakers. Kichwa was immediately adapted using Spanish graphemics, 
therefore in many texts the language is written with $\{q u\}$ as Quichua. Conversely, the 1998 Ecuadorian Constitution recognized the new graphemics after a series of meetings between academics, linguists and representatives of the communities and nationalities trying to better reflect the sounds of the language and a written unification (Ministerio de Educación 2009).

Haboud, Freeland, Howard, and Cru (2016) suggest that "following the Spanish conquest, Spanish became the de facto official language, throughout today's Latin America" (204). Recently there has been a focus placed on the revitalization of indigenous languages because globally minority languages have been dying out at alarming rates. Haboud et al. propose that one of the significant problems in the endeavor of language revitalization is precisely a lack of consensus in the numbers of indigenous speakers: on the one hand, many of those who recognize themselves as indigenous do not speak the language, and on the other hand, many people who do not self-identify as indigenous are bilingual. It is important to analyze the language-identity relationship since "many of the groups who have lost their language forcefully nonetheless maintain their identity, which is closely related to their sense of territoriality and worldview" (Haboud et al. 2016, 204).

Indigenous Kichwa speakers are considered as "minoritized" groups: both a demographic minority and a group exposed to unequal social relations. Moreover, it has been argued that "language shift from the Indigenous languages to a dominant European language (Spanish, Portuguese, English) is an inexorable, ongoing process associated with poverty, racism, linguicism, and linguistic and cultural insecurity" (Haboud et al. 2016, 201). The work of Knapp (2019) illustrates the number of Kichwa speakers on maps, focusing on language rather than on ethnic affiliation for the years 1950-2010, indicating that by 2010 the overall area of Kichwa speakers shrank, especially in the highlands.

Political indigenous mobilizations since the 1980 s put pressure on the government to act for indigenous groups and languages. Currently, the bilingual intercultural schools' system model, Modelo del Sistema de Educación Intercultural Bilingüe, Moseib, (Ministerio de Educación 2013) is in force. It seeks to respect people's learning rhythms, psychosocial aspects, creative capacity, and ancestral knowledge and aims to incorporate the expertise and understanding of other cultures that contribute to the harmonious development of the person and the environment. ${ }^{1}$

1 The Ministry of Education guides the government policies and principles on Bilingual Intercultural Education Programs (EIB). It also assesses and guarantees access to bilingual education, developing actions aimed at recovering the linguistic status of ancestral languages. Since 2018 there is an office in charge of handling and promoting a new ЕIв model. Their principles and mission statement can be found at: https://educacion.gob.ec/ direccion-nacional-de-educacion-intercultural-bilingue/. 
In these bilingual intercultural public elementary schools, Centro Educativo Comunitario Intercultural Bilingüe (СЕСІB), there are different levels of inclusion into the intercultural contact language (Spanish), depending on the age of the students. These include insertion into the semiotic process ( $5^{-6}$ years old), cognitive, affective and psychomotor strengthening (7-9 years old), development of skills and study techniques (10-12 years old) and research learning process (13-15 years old). The acquisition of a third language (usually English) has a lower percentage in each of the levels mentioned above, ranging from $5 \%$ in semiotic processes to $20 \%$ in research processes. For example, insertion into semiotic processes has $75 \%$ indigenous language, $20 \%$ contact language and $5 \%$ foreign language.

Haboud (2019) analyzes the contradictions and fragmentation between the well-defined linguistic-educational policies and their implementation. Even though they promote justice and equity for the indigenous peoples, the establishment of educational institutions for "quality education for all" which are included in the United Nations Sustainable Development Goals, do not involve indigenous languages and instead privilege monolingual learning. This is because most CECIB s are small schools, as the ones studied in Guayama San Pedro and Guayama Grande in Chugchilán, which lack pedagogical resources, libraries, books, and computers. High quality schools are mostly located in the urban centers of the countryside. Parents who can afford the costs of transportation involved in sending their children to the urban schools prefer such solutions.

This study focuses on how multicultural communication is shaped in ServiceLearning, SL. To do so, we focus on three SL activities that took place from 2018 to 2020 in two communities from the Andean paramo of Chugchilán, located in the heart of the Ecuadorian Andes. We first present a literature review in the field of SL and then move on to issues regarding intercultural communication before presenting the methods and data. Following that we present an analysis of how SL was performed together with the rural communities of Guayama Grande and Guayama San Pedro. The paper closes with a final discussion.

\section{Literature Review on Service-Learning}

Service-Learning, SL, has been applied as a methodology (Jacoby 2014), a teaching approach (Thomson, Smith-Tolken, Naidoo, and Bringle 2011), and a learning strategy (Tapia 2016) to efficiently catalyze service and learning for a deeper engagement between universities and communities. Campus 
Compact, a national organization in the USA, refers to SL as a "wide-spread, well-known practice" to develop mutually beneficial interactions between students and communities (Jacoby 2014, xvii).

Connecting students with diverse environments is a fundamental part of a holistic learning process; therefore, the knowledge gained from experiential learning plays an essential role in college students' education. Developing SL opportunities becomes a bridge between campus and communities. SL projects provide students the opportunity to learn how to apply their knowledge in a real-world setting. Working in projects where there is just mere contact with other cultures is not enough. It is important to interact with the goal of pursuing common goals. The literature highlights that what distinguishes SL from other active field methodologies is its capstone on participation, critical analysis, and assessment with the involvement of all participants.

To describe participation in SL, we build on the work of Carpentier (2016) who clarifies the concept of participation by comparing it with two adjacent concepts: access and interaction, and in this way, elucidates the differences between the three terms. Carpentier proposes that access is often understood as presence, interaction deals with the construction of socio-communicative relationships, and participation is linked to power and decision-making. Translating this to community engagement projects, the first step of access becomes effective when students and communities have the possibility to be present, meet each other and recognize the context. The second step goes further into the possibility of interacting with each other. Nevertheless, this makes no real change or transformation. Making a change and transforming reality is the third step of actual participation, which is also in the core of SL projects. If the social experience is not transformed into a personally relevant learning experience, then students will not fully benefit from the encounter.

SL is a type of informal, experiential education and a "philosophy of reciprocity" which is based on moving from charity to justice and from service to the elimination of need (Jacoby 2014). Welch (2016) suggests that the hyphen in its name (service-learning) is "purposeful in conveying reciprocity: through service one learns, and through learning one serves" (25). In this way, SL has manifold benefits: an excellent field experience for students, technical support, and knowledge transfer for the communities. Furthermore, Fung (2017) points out that SL hinges upon the development of "assessment criteria for learning from mistakes and difficulties, as well as from obvious successes" (91).

Moreover, SL is intended to be a model where the students comprehend that cultural systems are all equally complex. It cannot be a static vision of 
their own or the other's culture (Otten 2003). Hence, designing activities to promote a better understanding of other cultures and creating cultural competence can be challenging, predominantly when social, cultural, economic, and language barriers exist.

This can also be noted in the theorizing that Smith-Tolken (2019) does in relation to SL by reviewing the different concepts of "service" among the participants of community engagement projects. Smith-Tolken argues that students and faculty with a higher level of education "offer service as a way to gain experience of real-life situations," while communities, organizations and grass-root people receive service to have extra hands with the expectation of receiving scholarly or other creative inputs" (131). When there is a commitment by all groups in SL, they both grow and benefit from sustainable outcomes; otherwise, community-based projects can have no impact or even have negative effects on students, reinforcing stereotypes and equating service with assistance.

Jacoby too problematizes SL complexities and dilemmas, in particular on how to grapple with them constructively, recognizing both the affordances and constraints in community engagement. The author advises that resistance to community engagement "may occur when students [or staff] are not able to let go of long-held or family-based prejudices or self-righteous beliefs of their superiority over those who are different from themselves" (2014, 231). This means that it is necessary to prepare participants thoroughly in advance of field trips, and it is also important to work with the communities in advance, so as to prevent false expectations.

SL is performed through four iterative stages: preparation, action, reflection, and evaluation. Preparing participants beforehand is a fundamental step in the planning process; activities and fieldwork need to be significant for all participants in a way that they could realize that their engagement is relevant and meaningful for their own knowledge acquisition process. Engagement moves the objective of community outreach from mere "intervention" to a "joint venture" providing a two-way transfer of knowledge and learning opportunities, whether formal or informal (Yépez-Reyes, Leiva, and Moreano 2021). Critical reflection is in the core of SL, "the process of analyzing, reconsidering, and questioning one's experience within a broad context of issues and content knowledge" (Jacoby 2014, 26).

This type of reflection, as mentioned by Welch (2016), encourages participants to discuss about social responsibility, intercultural understandings, interdisciplinary learnings, environmental sustainability, knowledge acquisition, among others in search for social justice. Social justice addresses injustices with the goal to transform reality and pursue equal opportunities for all, 
"leaving no one behind", as has been proposed by the Sustainable Development Goals. Even though social justice is one of the pillars of higher education, universities are in an advantageous position "and there exists an imbalance" in their favor in comparison to the communities with which they work. It is within this scenario that working with the communities not for them is the objective of sL projects (Ríos, González, Armijos, Borja, and Montaño 2016).

Assessing and evaluating SL entails the systematic gathering and processing of information to understand the quality and effectiveness to achieve the desired goals. Since there are different types of participants in a SL project, it is compulsory to evaluate the impacts and measure the outputs, as well as the acquisition of learning outcomes.

The third step of the sL cycle, that of critical reflection, has been fundamental for this article. During the experience, students, faculty, and community members were invited to reflect on the project. First, during the preparation, the participants discussed their expectations and explored different ways to achieve their goals. The participants were encouraged to analyze their actions, so they had the chance to reflect on the results, what they learned and their achievements. This article took the transcendental phenomenology approach building on the information collected at this stage. Transcendental phenomenology emphasizes the essence of the phenomenon from the perspective of the participants involved who gained knowledge and acquired new meanings (Neubauer, Witkop, and Varpio 2019). This approach allowed recognizing the meaning of the lived experiences for students, faculty, and community members. The outcome of transcendental phenomenology is a description of the essence of the involvement including what was experienced and how it was experienced (Creswell 2013). Meaning is at the core of transcendental phenomenology. It focuses on a spatiotemporal reality perceived in first person: a consciousness of being and becoming aware of it. As Yee (2019) argues, consciousness is our awareness of what happens around us, it is intentional: "of concern in Phenomenology is not how experience arises but what resides in experience or the contents of the experience" (7).

We use the more traditional inquiry design of transcendental phenomenology, even though scholars have adopted interpretive phenomenology together with community-based participatory research to describe lived experiences (Bush, Singh, and Kooienga 2019). A conscious intentionality of participants to get involved in the experience, learn about it and reflect on it is the main source to analyze how sL developed in intercultural projects. We opted to focus on the foundations of transcendental phenomenology and applied it through a blended approach with SL critical reflection's stage. 


\section{Theoretical Framework on "Intercultural Communication"}

While SL is the educational setting whose aim is to bring together different cultures, multiple expectations and diverse worldviews, our framework for the analysis is the field of intercultural communication. The article questions how intercultural communication among mainstream Ecuador vs. indigenous Ecuador vs. United States can be shaped in SL.

Building on Carbaugh (2016), we seek to analyze intercultural communication from the lens of the participants in the projects. Given that this paper analyzes how communication takes place and how language gaps are superseded with the support and engagement of various groups, we focus on how different cultures are perceived from the eyes of the students and faculty involved, and how the expectations of the local communities are crossed by different ways of getting involved in the planned activities.

Carbaugh is critical about studies using quantitative measures, providing tendencies across populations to describe social phenomena, alluding that these studies do not really tackle intercultural communication as they do not analyze interactions among people but individual behaviors to explain tendencies. In this sense, "intercultural interactions bring into view vividly situated interactional dynamics [which] may offer deep insights" (2016, 34). Moreover, as mentioned before, and following Carpentier (2016), it is not only intercultural interactions that SL seeks but actual participation and involvement in shared goals.

Ferri (2018) points to that "each individual utterance represents a recognizable speech act in a defined system of rules, but at the same time it is placed in the unique context in which it is uttered" (19). However, everyone does not share the same universal understanding of meanings which could represent an obstacle to communication (Marandon 2003). In this way, intercultural communication is often faced with "the often-difficult negotiation of meaning in intercultural encounters" (Ferri 2018, 18).

Scholars argue that language shapes the way we think and understand the world (Boroditsky 2017). Culture is a fluid process that is continually changing and evolving, so that intercultural projects with actual involvement can lead to overcoming linguistic differences and overriding communication barriers between cultures. Bagga-Gupta and Rao indicate that language, regardless of the use of one language or another, is both "collaboratively achieved and constitutes a significant dimension of the construction of human realities" (2018, 3). In this way, intercultural communication occurs as a form of situated learning (Bagga-Gupta and Rao 2018; Corrius, De Marco, and Espasa 2016) in which 
learning happens on a specific and authentic context involving different cultures and languages in a real-life situation.

Language reflects a culture's shared values as an ethnic, linguistic, and social group. For instance, language is used as a social marker in Ecuador, which creates social stratification between ethnic groups and the language they speak. Taking a binary approach, Ecuadorian Spanish speakers are ethnically mestizo while most Kichwa speakers in Ecuador are ethnically indigenous. Many indigenous people try to vary their speech patterns when they leave their community, reflecting the Ecuadorian nation's multilingual nature.

The revitalization of Kichwa, which is particularly of interest for this study, and other indigenous languages can be analyzed as a reflection of glocalization, understood as a concept of cultural autonomy providing meaning-making in a global landscape (Roudometof 2015). To describe this, Roudometof (2015) uses the conceptual metaphor of refraction to explain glocalization: just as light or radio waves can deviate by passing through a medium of different density, glocalization is the result of global waves refracted through the local, it is therefore a dual global-local relationship.

Globalization and glocalization have enhanced the interchange of ideas and cultures at an accelerated rate. Cultural flows might change traditional manifestations of identity and shift it to a sameness or, in some cases, may emphasize these differences. Therefore, intercultural communication should be set to understand social groups through values, worldviews, interests, and structural inequalities (Zotzmann 2007, 266). Nevertheless, globalization has also accelerated an already ongoing process of displacement and shift of indigenous languages.

In the linguistic landscape of Ecuador, it is useful to refer to the traditional concept of diglossia which establishes the alternative use of two language variants according to different situations (Ferguson 1959). Ferguson terms the superposed variety in diglossia high language $(\mathrm{H})$ used for governmental, religion and aspects of "high" culture, and low language (L) for the local dialects and everyday activities. As Ferguson alerts: "An outsider who learns to speak fluent, accurate $\mathrm{L}$ and then uses it in a formal speech $[\mathrm{H}]$ is an object of ridicule" (329). The same happens on the contrary, using $\mathrm{H}$ language in familiar and intimate situations will result in embarrassing situations. In 1967, Fishman revisits Ferguson's diglossia and combines it with the understanding of bilingualism (the separate use of two languages) to showcase situations in which bilingualism happens without diglossia, or diglossia without bilingualism, and of course situations where both are present, or both are absent. We find this model of relationships between bilingualism and diglossia (Figure 1) very 


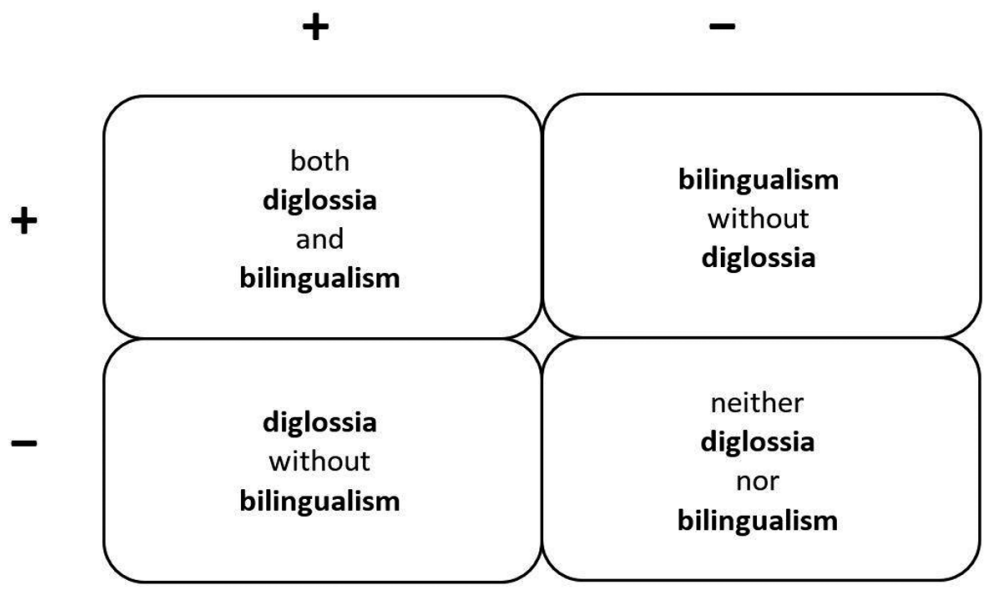

FIGURE 1 Relationships between bilingualism and diglossia (Fishman 1967, 30).

useful to describe the lived experience with the presence of simultaneous different languages, as will be shown in the coming section.

Due to the economic, social, education, and cultural changes within the country and global context, Kichwa-speaking populations are increasingly using Spanish in place of their native language. Under this condition, many indigenous people maintain Kichwa for informal and social situations (L), but for the most part, they use Spanish $(\mathrm{H})$ in official formal instruction and governmental circles. This can lead to loss of the less prestigious language (L). Prestige is given to a language due to linguistic contact, since the speakers, consciously or unconsciously, attribute values, whether positive or negative, to the languages or varieties they are in contact with (Haboud 1998). Therefore, it is difficult for subordinate languages to be considered prestigious since their validation is the result of long processes of domination and unequal power.

Today it is common for children, who attend bilingual or Spanish schools, to act as Spanish translators for the elders who mostly speak Kichwa. As Howard notes, the indigenous people are characterized by Kichwa-Spanish bilingualism; however, the same does not apply to the rest of the Ecuadorian population (mestizo) who "despite living in close proximity to Kichwa-speaking populations, are primarily Spanish monolingual” (2011, 190).

Just as social situations influence speech in the indigenous community, Spanish dialects are also considered social markers. Spanish spoken in Ecuador has linguistic borrowing (Field 2002) from Kichwa's lexical, syntactic, and intonational levels (Haboud and de la Vega 2008). For example, wawa, the Kichwa word for baby, is commonly used in Ecuador by the Spanish speaking population. The Ecuadorians of European ancestry -real or socially constructed- use 
vocabulary that is mostly used in standard Spanish to reflect their social status. Even though the Ecuadorian Constitution of 1998 celebrates the country's multiethnic nature, tensions exist between the use of minority languages and Spanish in everyday discourse.

\section{Methods and Empirical Context}

This paper centers on SL as a front-line practice applied to interdisciplinary community engagement programs since 2017 at Pontificia Universidad Católica del Ecuador (PUCE). Specifically, it refers to the community engagement project "Endogenous Development of Sigchos and Chugchilán". The research was conducted in two indigenous Kichwa communities: Guayama Grande and Guayama San Pedro.

The community of Guayama Grande is a small agricultural village with less than 250 inhabitants. This village is run by a group of young families in their 30 's who are working to promote their region as a hot-spot for community-centric agro-tourism. The community is located in the paramo between Chugchilán and the Quilotoa Lake, which is a large tourist attraction. Due to their location, a stable number of tourists hike from Quilotoa Lake to Chugchilán for lodging, passing through Guayama Grande. Because of the constant flow of visitors, the community decided to combine their agroecological practices with rural tourism, arranging their homes to host tourists interested in learning and sharing their ecological practices of agriculture in the highlands which are located 3,0oo meters above sea level.

Guayama San Pedro, on the other hand, is a small community located in close proximity to Guayama Grande and Quilotoa Lake. Guayama San Pedro was legally stablished as a political unit in 1994. Most of the population is made up of Kichwa speakers, which are a majority in the indigenous community. What makes the community unique is a large population of immigrants from all over the Cotopaxi province creating a Kichwa speaking enclave. The economic livelihood of the community is agriculture. The unique microclimates of the region allow crops to grow year-round. Some families have ownership of the most fertile land, and the rest of the members work in small lots in the highlands. Unemployed people tent to leave Guayama San Pedro and immigrated to small towns and cities close by. As for the educational system, most of the people who have a formal education are teachers in the school district.

Both Guayamas (Guayama Grande and Guayama San Pedro) are less than $10 \mathrm{~km}$ apart from each other, connected by an unpaved mountain road. There is just one bus line that runs daily to the main highway. Few members of 
the community own pickups or trucks that occasionally raise dust from the dirt trail. For the most, people walk from one community to the other or to Chugchilán, the bigger town in the area. Guayama Grande, regardless its name as "grande" means big in Spanish, is the smaller village. There are no stores in Guayama Grande, while in Guayama San Pedro it is possible to visit few small stores and depots with basic products. Middle and highschool age children need to travel to Chugchilán to attend school since in both Guayamas there are only primary schools: a single-teacher school in Guayama Grande and a school with one teacher for each grade (1st to 7 th) in Guayama San Pedro.

In this article we focus on three different SL activities taking place in these communities, one of them involving students and faculty from the Scripps College of Communication from Ohio University through a collaborative partnership, the other two activities involved students and faculty of PUCE from a wide variety of disciplines.

As taken up in Literature Review on Service-Learning an outstanding feature of SL vis-à-vis other methodologies is critical self-reflection. All participants are invited to assess each activity performed, to learn from their own mistakes and celebrate the achievements. Critical reflection is embedded in all activities to understand, analyze, and sometimes reframe actions throughout the project. Along the project, we conducted self-reflection surveys to better understand how intercultural communication happened at different levels.

Two surveys were used to collect data during the project, one was available from PUCE's Community Outreach Department and included demographic questions, three closed rating scale questions about planning, participation and perceived social transformation, and an open question about "participants' accounts" to which we refer in this article. It is important to mention that this survey was only available in Spanish, and some community participants asked their children to read and fill in their answers, as some elders did not understand the language or were illiterate. People from Ohio were not asked to fill in the survey. The second survey was specifically conducted for the third project about reading promotion. The questions and answers are mentioned in Reading Promotion.

Communication during the SL project was a challenge due to the linguistic diversity of the three groups: PUCE (Spanish), Ohio University (English) and the communities of Chugchilán (Kichwa). The global digital divide affected the participants in different ways. For example, the students from Ohio University have grown up with access to advanced technology. Secondly, most students from PUCE come from the middle and upper-class segments of Ecuadorian society. Compared to the indigenous communities in rural Ecuador, the groups from PUCE and Ohio University had access to technology that is not 
yet common in this rural area, due to a lack of infrastructure and economic resources. Most participants from Chugchilán in this project do not have access to a computer at home. In contrast, most of the students from Ohio University and PUCE are acquainted with computers, devices, and the internet on a regular basis. Regarding languages, people from Chugchilán speak Kichwa as their primary language, Spanish as a second language and some children had a little sense of English which they learn at school as a foreign language. We leave aside the issue on English teaching for another study, but we will mention that there is a lack of competencies in English as a foreign language of teachers particularly in rural schools. Students and faculty both from PUCE and Ohio do not speak Kichwa.

\section{Analysis of three SL projects}

We build on Fishman's model (Figure 1) to represent how diglossia and bilingualism took place in the different activities performed, which are illustrated in Table 1 and explained in the coming sections.

\section{Community-based Tourism}

The sL project in the community of Guayama Grande developed into an interdisciplinary venture ranging across multiple departments at PUCE. The partnership with the community and PUCE started with the programs focused on nutrition and medicine, long before the Communication Department was invited to participate. The SL activities of the Nutrition School were implemented over two semesters at which time students and faculty visited most of the families' homes and trained the community on food handling techniques, as well as helping them to decide the menus for the tourists. The training took place entirely in Spanish, as students and faculty did not speak Kichwa. However, during the training sessions, comments and reflections among the community participants did happen in Kichwa, sometimes translated for the people from PUCE. During this time, students and faculty learned about different plants in the area and how they are used for cooking and medicine. The native plants were presented to the visitors using their Kichwa name; and PUCE staff explained menus for the tourists in Spanish and taught urban preparation practices for recipes (Table 1). Communication students were invited to take part in the project and help with marketing to attract future visitors. The students and faculty were some of the first visitors to use some of the new rural 
TABLE 1 Applying Fishman's model of diglossia (D) \& bilingualism (B) to SL interactions.

$+\mathrm{D}+\mathrm{B}+\mathrm{B}-\mathrm{D}+\mathrm{D}-\mathrm{B} \quad-\mathrm{D}-\mathrm{B}$

Nutrition \& HeALTH

Food health \& care

PUCE

Native plants

Community

Recipes

PUCE

Tourism

Arrival

PUCE, Ohio,

$\begin{array}{ll}\text { Work } & \text { Community } \\ \text { performance } & \text { PUCE, Ohio, Community }\end{array}$

Closing PUCE, Ohio, Community

POTTERY \& WEAVING

Training sessions

PUCE, Community

Storytelling PUCE, Community

READING PROMOTION

School work

PUCE, children

lodgings that were recently built to accommodate more tourists and provide an economic boost to the community.

At the same time, PUCE's College of Communication signed a partnership with Scripps College of Communication at Ohio University. This presented the opportunity for a joint project between both universities working together in Chugchilán. In this way, participants from Ohio University could learn about the countryside and apply innovative vr-cinema which was new to PUCE. The participants from Ohio University were composed of two faculty members and one student. The PUCE group was composed of 20 students and four faculty members. The participants were divided into five rural lodgings and had the chance to meet and share three days with at least 20 members of the community. As for the communication pieces, all members of the group were divided into four specific topic domains: tourism attractions, experience-based tourism, ecological farms, and ancestral knowledge. Each group was able to select the media they wanted to apply to their area of study (i.e. vr-cinema, 
photography, audio, video, etc.). This work was used to design a website that is now managed by the community of Guayama Grande to promote their facilities for community-based tourism: www.guayamagrande.wordpress.com.

While working with the community, it was apparent that some people were more familiar with technology than others. There were noticeably different perspectives ranging from technology advanced to a basic understanding. While the participants from Ohio University were primarily interested in the potential of immersive technologies (digital), the participants from PUCE were more knowledgeable on traditional reporting (print, audio and video), and the local inhabitants focused on the environment (nature). In this landscape, intercultural communication occurred as situated learning, promoting interaction and participation because of a shared will to work together as the achievement of the project goals was only possible with the collaboration of everyone in the group.

People from Ohio learned about Kichwa for the first time during this trip. One issue that became apparent at the beginning of the project is that PUCE's students and faculty did not know any Kichwa. Aside from the loanwords that are part of Ecuadorian Spanish -blended with Kichwa's syntax and construction- Kichwa is not used widely. The fact that Guayama Grande conserves a substantial population of indigenous people has made it possible to maintain the language.

Applying Fishman's model of diglossia and bilingualism, it can be said that at the beginning the three linguistic groups stand in the quadrant of bilingualism without diglossia, with separated languages without a meeting point, for example, not trying to adapt any of the three languages to the circumstances (Table 1). For instance, the English word storytelling was never translated to Spanish or Kichwa since the English term was perceived as connected to cutting-edge technologies in narratives. The Kichwa word chakiñan -literally chaki $=$ foot, $\tilde{n} a n=$ way - a loanword in the Ecuadorian Spanish was always used in Kichwa to refer to a narrow walking path around the mountain, and the Spanish word barro, referring to clay for making pottery was never translated to Kichwa nor English. Each of these words represents a unique way to conceive the world and the speakers' culture and identity and they were used by all participants regardless of their primary language.

Once working in teams during the activity, it was clear that most PUCE members had previously acquired enough English language skills to communicate with the participants from Ohio University but were not comfortable with their fluency in English when it came to complex discussions. Due to the lack of oral English language competence, communication was hampered because of their inability to communicate. Those confident with their English abilities 
were able to establish conversations with participants from Ohio University. In the words of Fishman (1967), this could be referred as a type of bilingualism without diglossia.

Members of the community of Chugchilán had a basic understanding of English but were even more shy to use it in public. The student from Ohio University had basic Spanish skills but reverted to English once she realized that most students from PUCE could follow discussions in English. Many members of the community could not follow conversations in English; faculty members from Ohio University did not know Spanish but managed to communicate both in English and gestures with the help of the students. Members of the local community could all understand Spanish except for some of the older adults who were not eager to speak Spanish. Children worked as translators as they were more fluent in Spanish than their parents and grandparents. Children of Guayama Grande could grasp a little English, which they have learned in school. Following Fishman's model this communicative situation could be termed as both diglossia and bilingualism (Table 1).

Members of the local community valued their knowledge of the natural surroundings. This gave all participants a better understanding of the fundamental role played by the environment and a sense of respect for local knowledge. The knowledge on cutting-edge technology of the participants from Ohio University helped the group get 360 -degree images and sound, which put them on a privileged position. In contrast, PUCE members embraced their role of traditional media specialists and tutors of the children from the community. Because PUCE students also had technological expertise, this helped intercultural communication in SL develop smoothly. In this way, all participants acquired some type of new knowledge, achieving the goals of SL, besides that all were left with fond memories and a spirit of comradeship. This project was a good opportunity for a national and international exchange of experiences and knowledge among different cultures that happened to work together and share experiences. This intercultural approach allowed all participants to navigate in this diverse context and reality, acknowledging the differences and understanding the diversity.

\section{Pottery and Weaving}

A second SL activity in Guayama Grande consisted of pottery and weaving workshops. Weaving textiles and kneading clay are activities that, despite being a part of the everyday life of local communities in the past, are now being forgotten. Most families raise sheep, but they do not shear them to use the 
wool. They market the fleece directly, without sorting or preparing the fleece. Reintroducing handlooms in the community was an interesting experience; participants suggested patterns and designs for weaving. This gave community members the chance to add value to the items they sell.

Weaving sessions were full of Kichwa conversation. There was also a blending of Kichwa and Spanish when youngsters from the community used short comments. In small circles, the indigenous language was preferred, and PUCE students and faculty were clear about their inability to share personal stories told in this very personal time spent doing handicrafts. The same can be said of the pottery activities.

In this activity, storytelling was again used to explain the local communities' connection to nature. The handicrafts were full of narratives of the rural community. The workshops allowed innovative handicrafts to embody the narratives and the wildlife of the paramos. Clay kuys -guinea, pigs-, wolves, and birds were some of the pieces that were made. Art students were profoundly interested in local stories and legends, learning how those are connected to culture and to the linguistic understanding of the world. Back at the university, some of the handicrafts acquired augmented possibilities of movement and animation, enhancing traditional characteristics with technology brought from Ohio University in previous activities.

For the assessment, the perception survey supplied by PUCE Community Outreach Department was conducted in Spanish. It is important to mention that even though these forms should acknowledge the language of rural participants, they are all written in Spanish which until now has never been questioned. Fifteen community members responded, 14 from the group 26-65 years old and one young adult (group 18-25 years old). This survey focused on the involvement of the participants in the project and the usefulness of the interaction. When community members were asked to provide feedback on the project, the president of the Guayama Grande's community answered: "The handlooms that the compañeras are weaving are something new, and for example, here we waste sheep's wool. Maybe we would continue making yarn from sheep's wool and start doing some crafts and then offer them to tourists, who are always crossing through our territory, and we have had nothing to offer them from our community." We did not translate the word compañeras (fellow women) as it is a Spanish word often used while speaking in Kichwa; nonetheless, its male Kichwa correspondent mashi is usually used both in Kichwa and in Spanish conversations as well.

During the workshops, children often acted as translators for the storytellers when the ideas were difficult to express in Spanish for the elders. In this 
activity, both diglossia and bilingualism co-occurred to work together and learn from each other during the handicrafts' workshops (Table 1).

\section{Reading Promotion}

An engaging activity performed by Communication, Literature and Arts students from PUCE has been reading promotion in Chugchilán. In 2020, before the start of the pandemic, the project worked with children and teachers at the bilingual intercultural public elementary school, Сесів Belén 15 de Julio in Guayama, San Pedro. This school is made up of 10 teachers and 136 students. It also worked with 31 students and one teacher at the school of Guayama Grande, Сесів José Manuel Chugchilán. In both schools, students are between 4 and 13 years old. Through different activities involving art and literature, children were invited to read, write, and share stories. However, all of these were in Spanish as the university students had no knowledge of Kichwa. In Belén 15 de Julio we observed that the use of Kichwa is reserved for more casual spaces like recess and interpersonal communication, but children and teachers can easily move from Kichwa to Spanish and vice versa.

For the assessment of the SL activity, we conducted a survey in Spanish for PUCE students that included 10 open-ended and one closed-ended questions. Only nine of the 13 students $(69 \%)$ responded to the survey. Below we present some of the questions and answers which provide an overview about the activity and a sense of personal reflection where students speak freely about the experience, including our reflections:

Doyou speak another language besides your mother tongue? None of the students spoke Kichwa as a secondary language, yet six out of nine stated they spoke English at a basic level. This remark reflects the perceived/actual value of learning a foreign language even when Kichwa can be used in Ecuador. The value placed on learning foreign languages correlates to prestige and status and could reinforce how language is used as a social marker. Also, it indicates how the educational system in Ecuador places more value on the acquisition of an international (foreign) language over an indigenous one.

Do you believe there are "difficulties" derived from having Kichwa as a mother tongue in the school learning process? Most of the students commented on the importance of Spanish in the education system and how speaking a minoritized language can interfere in the learning process. As one of the students highlights: "The educational system is built for Spanish language speakers, thereafter children who speak Kichwa and Spanish as a second language are disadvantaged". 
Students struggled with the fact that they did not speak Kichwa, and in some circumstances, their counterparts only had intermediate Spanish skills. Students were surprised that the indigenous community spoke a different Spanish dialect or, in some cases, used a Spanish with a different syntactic construction. As one of the students points out: "There were too many [communication] difficulties since people from the community could not answer our questions since they did not know many terms of the Spanish language. While we did not know a single word in Kichwa". Haboud (2019) highlights that there is a long-lasting fragmentation in Ecuadorian society regarding language diversity, which it has been unable to completely overcome despite the good will of the intercultural schooling programs. This leads Ecuadorians to feel embarrassed about the languages, cultures and identities that are different from the dominant language, culture, and identity in the country. The point is that prestige is also present when tackling bilingualism with marked differences between prestigious bilingualism (e.g. English-Spanish) and minoritized bilingualism that becomes a burden to communication, as the respondents suggest.

Doyou think that everyone in Ecuador should speak Spanish? The respondents explained how important it is to learn Spanish and the value to keep Kichwa alive. One student claimed that the government system had forced Kichwa speakers to adopt Spanish and the lack of effective policies to prevent language discrimination: "The Ecuadorian State builds the public sphere and rights for people who speak perfect Spanish. Therefore, they must overcome a language barrier; however, there should not be discrimination by the Ecuadorian State itself against people who speak a different first language". Even though the students display a will to revitalize this indigenous language, this can only happen if the population can find a value for the language in terms of personal or professional reasons.

Do sL experiences help one develop personally and professionally? A student stated: "Yes, they do. It allows you to have contact with people you would not normally be around. It also lets you understand that the world is made up of diverse people and that this comprehension should affect your daily life".

The reading promotion activity had little contact with adults of the communities, apart from the schoolteachers. The main participants were children and university students. Applying Fishman's quadrants (Figure 1), the linguistic relationship this time was a type of diglossia without bilingualism, as the two language groups (Spanish and Kichwa) functioned as a unit with limited linguistic repertoires. These two groups tried to barely communicate with the others for the development of the activities performed, but the actual conversation happened in the language of their intragroup (Table 1 ). 
The goal of SL is not a one-way flow of knowledge but that all parties involved gain from the experience. We realize that most of this project was a challenging way for students to gain cultural competency skills, be respectful, and interested in learning about different cultures. The communities felt that the project let them get involved in something different from their daily work and responsibilities. As for linguistic skills, we realize that bilingualism enriches intercultural communication.

\section{Final Discussion}

SL has the goal to reinforce the value of a positive learning experience for all participants. Throughout the three activities, participants understood the complex role that culture plays in intercultural communication; faculty were able to put in practice learning skills in real-life situations; and the communities involved in SL processes have been able to share their new knowledge and skills. It also validates community engagement as a crucial way to exchange knowledge, technology, and culture from one group to another.

We found that multilingual communication was a complex endeavor ranging from no interaction between different language groups, where neither diglossia nor bilingualism was attained. As students, faculty and members of the communities learned about each other they started to value each other's knowledge. This situation changed depending on the relationship of diglossia and bilingualism.

Being open-minded during these types of projects allows participants to appreciate experiences in a different way. The participants did not end with a romantic, idyllic view of life in the countryside but with an appreciation of the world and different worldviews. The community-based tourism project allowed students and faculty, from PUCE and Ohio University, to gain a better understanding of the harsh conditions in which rural communities live and how it is linked to their low social-economic status. It was also an encounter to learn about why Kichwa is a complicated language to grasp, since it has a completely different syntax compared to Spanish and English.

To answer the question guiding this study, we believe that SL constitutes a valid methodology to develop intercultural communication skills. Bringing these diverse groups together created a positive environment where social change can take root. The field remains open for research in various topics where the revitalization of indigenous languages remains a debt, we owe our ancestors and a venture to include in an intercultural world. 


\section{Abbreviations}

$\begin{array}{ll}\text { SL } & \text { Service-Learning } \\ \text { MOSEIB } & \text { Intercultural Bilingual Schools' System Model } \\ \text { CECIB } & \text { Bilingual Intercultural Public Elementary School } \\ \text { EIB } & \text { Bilingual Intercultural Education } \\ \text { PUCE } & \text { Pontificia Universidad Católica del Ecuador } \\ \text { vr-cinema } & \text { Virtual reality cinema }\end{array}$

\section{References}

Bagga-Gupta, Sangeeta, and Aprameya Rao. 2018. "Languaging in Digital Global South-North Spaces in the Ttwenty-First Century: Media, Language and Identity in Political Discourse." Bandung Journal of Global South 5 (3): 1-34.

Boroditsky, Lera. 2017. "How Language Shapes the Way We Think". TedWomen, 14:05. URL: https://www.ted.com/talks/lera_boroditsky_how_language_shapes_ the_way_we_think

Bush, Erin J., Reshmi L. Singh, and Sarah Kooienga. 2019. "Lived Experiences of a Community: Merging Interpretive Phenomenology and Community-Based Participatory Research." International Journal of Qualitative Methods 18: 1-12.

Carbaugh, Donal. 2015/2016. "Intercultural Communication as a Situated, Culturally Complex, Interactional Achievement." Russian Journal of Linguistics 19 (4): 33-42.

Carpentier, Nico. 2016. "Differentiating Between Access, Interaction and Participation." Conjunctions: Transdisciplinary Journal of Cultural Participation 2 (2): 7-28.

Corrius, Montse, Marcella De Marco, and Eva Espasa. 2016. "Situated Learning and Situated Knowledge: Gender, Translating Audiovisual Adverts and Professional Responsibility." The Interpreter and Translator Trainer 10 (1): 59-75.

Creswell, John W. 2013. Qualitative Inquiry and Research Design: Choosing Among Five Approaches, 3rd ed. Los Angeles, CA: Sage Publications Ltd.

Ferguson, Charles A. 1959. "Diglossia." Word 15 (2): 325-340.

Ferri, Giuliana. 2018. Intercultural Communication: Critical Approaches and Future Challenges. London: Palgrave Macmillam.

Field, Fredric W. 2002. Linguistic Borrowing in Bilingual Contexts. Netherlands: J. Benjamins.

Fishman, Joshua A. 1967. "Bilingualism With and Without Diglossia; Diglossia With and Without Bilingualism." Journal of Social Issues 23 (2): 29-38.

Fung, Dilly. 2017. Connected Curriculum for Higher Education. Chicago: UCL Press.

González, Juan C., Verónica Yépez-Reyes, and Elizabeth García. 2019. “Vinculación con la colectividad: una propuesta de gestión." Revista Killkana Sociales 3 (2): 29-36. 
Haboud, Marleen. 1998. Quichua y castellano en los Andes ecuatorianos: los efectos de un contacto prolongado. Quito: Abya-Yala.

Haboud, Marleen, and Esmeralda de la Vega. 2008. "Ecuador." In El español en América. Contactos lingüísticos en Hispanoamérica, edited by Azucena Alcaine, 161-188. Barcelona: Ariel.

Haboud, Marleen, Rosaleen Howard, Josep Cru, and Jane Freeland. 2016. "Linguistic Human Rights and Language Revitalization in Latin America and the Caribbean." In Indigenous Language Revitalization in the Americas, edited by Serafin CoronelMolina and Teresa L. McCarty, 201-224. New York: Routledge.

Haboud, Marleen. 2019. "Educación intercultural bilingüe en el Ecuador. Entre la contradicción, la fragmentación y la esperanza." Elad-Silda, no. 3 (November): 1-20. Howard, Rosaleen. 2011. "The Quechua Language in the Andes Today: Between Statistics, the State, and Daily Life." In History and Language in the Andes, edited by Paul Heggarty and Adrian J. Pearce, 189-213. New York: Palgrave Macmillan.

Jacoby, Barbara. 2014. Service-Learning Essentials. Questions, Answers, and Lessons Learned, Higher and Adult Education Series. USA: Jossey-Bass.

Knapp, Gregory. 2019. "The Changing Kichwa Language Map in Ecuador." In Handbook of the Changing World Language Map, edited by Stanley D. Brunn and Roland Kehrein, 1-12.

Marandon, Gérard. 2003. "Más allá de la empatía, hay que cultivar la confianza: Claves para el reencuentro intercultural." Revista CIDOB d'Afers Internacionals, 61-62: $75^{-98 .}$

Ministerio de Educación. 20o9. Kichwa. Yachakukkunapa Shimiyuk Kamu. Quito, Ecuador: Ministerio de Educación.

Ministerio de Educación. 2013. Modelo del Sistema de Educación Intercultural Bilingüe (MOSEIB), edited by Subsecretaría de Educación Intercultural Bilingüe. Quito, Ecuador: Ministerio de Educación.

Neubauer, Brian E., Catherine T. Witkop, and Lara Varpio. 2019. "How Phenomenology Can Help Us Learn from the Experiences of Others." Perspectives on medical education, 8 (2): 90-97.

Otten, Matthias. 2003. "Intercultural Learning and Diversity in Higher Education." Journal of Studies in InternationalEducation (Association for Studies in International Education), 7 (1): 12-26.

Ríos, Renato, Juan C. González, Ekaterina Armijos, Karina Borja, and María D. Montaño. 2016. "Estrategias para el arquitecto intérprete: el consultorio en el laboratorio de los paisajes vivos." Arquitecturas del Sur 34 (49): 22-31.

Roudometof, Victor. 2015. “Theorizing Glocalization: Three Interpretations." European Journal of Social Theory 19 (3): 391-408.

Smith-Tolken, Antoinette. 2019. "Developing a Substantive Theory of Service Interactions Between University Students and Third Sector Organisations." In 
Vinculación con la colectividad: una propuesta de gestión, edited by Juan C. González, Verónica Yépez-Reyes and Elizabeth García, 131-150. Quito: Centro de Publicaciones PUCE.

Tapia, María N. 2016. Inserción curricular del aprendizaje-servicio en la Educación Superior. Buenos Aires: Ediciones CLAYss.

Thomson, Ann M., Antoinette R. Smith-Tolken, Anthony V. Naidoo, and Robert G.

Bringle. 2011. "Service Learning and Community Engagement: A Comparison of Three National Contexts." VOLUNTAS: International Journal of Voluntary and Nonprofit Organizations 22 (2): 214-237.

Welch, Marshall. 2016. Engaging Higher Education. Reprint, USA: Stylus Publixhing. Yee, Sye Foong. 2019. A Phenomenological Inquiry into Science Teacher's Case Method Learning. Singapore: Springer Verlag.

Yépez-Reyes, Verónica, Jimena Leiva, and Marcelo Moreano B. 2021. "Merging ServiceLearning and Life Stories: Communication Studies under the Ignatian Pedagogic Paradigm." Best Practices in Jesuit Higher Education, no. 1: 154-169.

Zotzmann, Karin. 2007. "Globalization and Intercultural Communication." Culture, Language And Representation. 4 (4): 253-268. 